\title{
Stakeholder-driven Learning Analysis: A Case Study
}

\author{
Ingrid Guerra-López, Wayne State University \\ Alisa Hutchinson, Wayne State University
}

\begin{abstract}
Instructional analysis is intended to generate meaningful data that fuels design decisions. An important consideration is the transfer context, where learners will perform the skills gained through instruction. This context is often implicit in on-the-job training but many educational programs that build workplace skills are far removed it and may miss crucial design insights. This case study describes an analysis for the design of a graduate degree program using a stakeholder-driven approach rooted in the transfer context to ensure relevancy of the design. It also describes innovative approaches to integration of data from disparate sources and scenario-based recommendations.
\end{abstract}

Keywords: instructional analysis, instructional design, needs assessment, stakeholder involvement, transfer context, higher education, curriculum design

\section{Introduction}

Analysis is one of the initial steps in the instructional design process; it typically involves investigating the targeted instructional needs, skills, learners, and/or context to gather information necessary to make effective design decisions (Dick \& Carey, 1990; Molenda \& Boling, 2008; Smith \& Ragan, 1999; Tessmer \& Richey, 1997). When they are properly understood and addressed, contextual influences in particular can provide crucial support for transferring learning gains to realworld performance settings, or what is called the transfer context (Tessmer \& Richey, 1997). When training is provided in an organizational setting, it is likely that many or all of the people involved in the design process have some implicit knowledge of the transfer context as it is their shared workplace. However, learning experiences often take place in settings removed from transfer context. Higher education is one such example, where students go on to work in a broad and disparate array of settings outside of academia. For those tasked with curriculum development in higher education - particularly developing or refining degree programs or professional training - incorporating the transfer context during front -end assessment and analysis may represent an innovative and effective way to ensure that students' learning experiences are relevant and enduring beyond the classroom (Kaufman, Watkins, Guerra, 2002). However, there is much to be discovered about how curriculum planners and decision-makers can best use front-end analysis processes to ensure calibration between the curriculum design and the transfer context.

Given contemporary demands on higher education institutions to provide students with skills that will be valued in the marketplace, the inclusion of practitioners and future employers in a needs assessment (GuerraLópez, 2012), and related analysis processes is a valuable approach for alignment with the transfer context. Although generally scarce in the literature, some studies have sought to investigate the role of stakeholders from transfer contexts in curriculum development for degree programs in higher education. These have included a multi-stakeholder model for validating curriculum topics via ranking sheets, surveys, and focus groups (Autry et al., 2001); a competency-based model that incorporates input from industry and faculty representatives (Sutcliffe, Chan, \& Nakayama, 2005); and needs assessment that mapped competencies for curriculum development by integrating employer, practitioner, and academic input (Jeffrey \& Brunton, 2010; Meyer \& Bushney, 2008).

While it is heartening to see an emphasis on these stakeholders, the existing studies lacked sufficient detail regarding data collection methods (including the types of data gathered) and analysis procedures, as well as clear alignment between findings and recommendations for curriculum decisions. Without sufficient specificity, it is difficult to gain insight into how stakeholder data can be used or to appreciate the advantages and short- 
comings of particular methods in particular contexts. Curriculum design teams in particular may have limited resources to conduct comprehensive instructional analyses, so it is especially important to share the challenges and solutions that emerge from similar constraints in authentic settings. These lessons can also be valuable to other instructional designers and practitioners outside of academia who may be removed from transfer contexts important to their learners, who may have limited resources for thorough front-end analysis but seek to make the best use of the data they are able to gather.

In this case study we describe analysis techniques used to define the design requirements for a graduatelevel program within the international development sector, with a special focus on stakeholder participation to maximize the transfer value of this degree. The analysis team had an accelerated timeline and constraints on data collection, which led to innovative approaches to analysis and reporting of findings to make the best use of available data. In light of these issues, the key question we have sought to address in this case study is: assuming multiple methods and multiple stakeholders are included in the curriculum analysis process, how can the needs analysis team best collect, calibrate, analyze, and synthesize data to support meaningful decision-making within given resource constraints? The goal for this case study was not to present a textbook example of needs analysis or prove a particular hypothesis, but rather to share the insights that emerged from the complexities and compromises inherent in real world settings.

\section{Context}

The primary client for this case study was a large international development organization that was providing technical assistance to a regional institute with affiliations to a major university in Eastern Europe for the purpose of developing educational programming in food security. The institute works in the food security sector in Eurasia, offering interdisciplinary research, policy, and technical services in the region with a complementary goal of developing a network of academic and research institutions (regional and international) that will contribute to improved agricultural and food security policies both in Eurasia as well as globally. The funding agency had played a key role in the initial development of the institute as part of an arrangement with the national government of the institute's host country, which included the establishment of a knowledge management center and learning program. Developing local capacity is an important strategic goal for both the funding organization and the institute; thus this learning program was intended to build a pool of professionals with advanced food security expertise to work in the region covered by the institute, in response to the international community priorities around ensuring food security. Research was conducted on the various sources impacting food security, and one key area identified as a priority was advanced food security expertise. This was the basis for a recommendations to establish a master's degree program in food security with an emphasis on hands-on application. It is in this context that front-end curriculum analysis described here occurred.

The needs analysis team was brought in at the point when relevant, documented data about the needs of transfer-context stakeholders could support and accelerate the design and development of the curriculum. The clients were able to articulate the basic goals of the analysis; they were not, however, able to define the best approach to accomplish those goals. Particular areas of interest to the curriculum development team included content topics, program structure, pedagogy, delivery format (specifically online vs. face-to-face settings), and capacity for e-learning. Tasks for the needs analysis team included identifying the skill and knowledge needs of transfer-context stakeholders and other relevant benchmarks; analyzing and integrating the resulting data; and presenting curriculum recommendations driven by the evidence and analysis.

\section{Methodology \& Findings}

The stakeholder analysis approach described here consists of reiterative rounds of data collection and analysis. Phase 1 consists of needs identification based on input from end-users, which provided the framework for the second phase of the curriculum analysis. While phase 1 was focused on identifying the actual learning needs, key tasks for Phase 2 included further data collection and analysis to support the generation of recommendations related to: curriculum topics; e-learning capacity; curriculum format and delivery; content and pedagogical issues; and language of instruction.

\section{Phase 1: Needs Identification and Analysis}

The initial phase of the needs analysis was centered on identifying needs that the institute's educational program was intended to address. One important consideration from the outset was ensuring that external stakeholders from the five countries targeted by the institute for this program were given a substantial voice to represent the transfer context. As mentioned earlier, the institute's mission includes a commitment to building professional and educational networks within the region, and a driving purpose of this project was to develop professional capacity in the region via graduate-level training in food security. In order to effectively achieve this, it was necessary to understand the perspective of end users (including potential employers of future graduates of the program), to identify the skills and knowledge that they believed were necessary to build the field as well as the perceived obstacles to participation. As such, the team decided to use prospective endusers, potential employers of graduates, and food security professionals already working in the field as anchors for the data collection during the identification phase, augmenting their opinions with expert reviews as well as competitor benchmarking. Prospective endusers consisted of a variety of individuals that may have been working within food security in the public or private sectors, with some education and experience in relevant fields, but who lacked a professional or specialized level of technical knowledge, skills, and expertise in food security. Potential employers were identified as mid to high-ranking officials and policy-makers from relevant government ministries, development agencies, and private sector companies. Targeted experts included researchers and practitioners from various Eurasian universities and food security institutes and outreach organizations working directly with farmers in the field. 
Rather than turning first to faculty and using their opinions to set the template for further data collection and analysis, this needs analysis project worked from the outside in, using end-user data as the framework for the curriculum analysis, then moving inward to contextualize findings to the specific academic setting (in this case one major university in Eastern Europe) to ensure close alignment between market demand and supply.

Initial data collection took place during a series of face-to-face workshops with 28 participants who were practitioners and five participants who were faculty at various universities in the region. Participants in this convenience sample were selected to include a range of professions relevant to food security including government officials, policy makers, researchers, program managers, private sector leaders, technical specialists, and trade association leaders. Because people in these positions would be the future employers and colleagues of the target audience (as well as potential students themselves), their input would provide the necessary data to align curriculum recommendations with the needs of the professional workplace. Without their voice, the analysis would be relying on assumptions and perceptions of faculty and/or the development team members who may be biased based on their own area of expertise or country of origin. Essentially, the curriculum would be driven by supply (of current researcher and faculty expertise and preferences), rather than the needs of the region. The three-day workshops were held in a central city to minimize travel burdens, ensuring that attendees from all target countries would be represented; distribution ranged from two to seven subjects per country. Participants were organized into workshop groups by country (four country-specific groups in total, as one group included a smaller group of representatives from two countries); a fifth group included international professionals in the international development sector with expertise in food security. Each workshop was approximately two hours of roundtable discussion, facilitated by an experienced professional with both an academic and practitioner background in front-end assessment and analysis of learning and performance, with assistance from two junior facilitators who also took notes during the workshop to capture participant ideas and recommendations for later analysis.

During each workshop, in-depth discussions lasting approximately two hours each were held around performance requirements, job tasks, skills and knowledge, required resources, and learning formats. For each topic covered in the workshops, the semi-structured conversation explored elements of an ideal or desired state (what skills, knowledge, and job roles would be essential to ensure the performance requirements were met) as well as current challenges faced by participants in realizing the exemplary state. Each workshop group articulated content needs in a manner unique to the national and professional perspectives of the participants. In order to integrate the resulting data sets, four lenses were used to view participant perceptions including: current job tasks (duties or expertise as described by individual participants in relation to their own professional roles and requirements); necessary skills (tasks or expertise identified as important, desired, or critical for supporting food security); gaps/anticipated needs (tasks or expertise identified as particularly deficient either currently or in the future food security); and desired content (any topics that participants specifically mentioned they would like to see included). In addition, the workshops included discussions of available resources and barriers to participation in such learning programs, particularly in relation to e-learning possibilities.

As mentioned, participant opinions were recorded by a junior facilitator, translated into English (four of the five focus groups were conducted in Russian), and then validated by the facilitator as well as development agency observers who had sat in on the workshops and spoke both Russian and English. A qualitative inquiry approach was applied to the resulting notes in order to code and integrate major themes that emerged from each of the five workshops. This involved a reiterative process of reading the workshop minutes, taking notes, and then rereading the data to identify prominent ideas and issues. A thematic content analysis was conducted, which consisted of categorizing topics into three major areas: course content, course format, and resources. Subsequently, additional conceptual domains were developed within each area to provide a framework for grouping individual topics within the theme. As an example, within the course content area, five conceptual domains were identified: socio-political topics; management and leadership topics; monitoring and evaluation topics; bio-physical topics; and farmer outreach. Similarly important themes relating to course formats, delivery modalities, and existing resources and challenges were also identified. Workshop notes were then reviewed again and each mention of a topic was recorded in a master matrix under the appropriate country and discussion lens (as described above) to track how often topics and conceptual domains were mentioned overall, as well as frequency counts per country and per lens for topics and conceptual domains. Two additional food security experts that did not participate in the workshops, but were asked to review the initial findings and suggested additional curriculum topics that were potentially relevant to the program.

Once the initial data analysis had been completed, a preliminary report was prepared to outline preliminary needs as identified by participants. These included 94 potential course topics spread among the five conceptual domains. In terms of delivery options, many participants expressed an interest in e-learning formats (including fully online and blended courses) as well as options for both short- and long-term courses with options for either certification or a formal graduate degree as potential program outcomes. Pedagogy was another important concern, with participants emphasizing hands -on instruction with opportunities to apply skills and knowledge; integrated international experiences; userfriendly technologies; inclusion of the most current data and tools; and a sensitivity to local and national contexts and issues within the region. Although e-learning was a preferred option, concerns were also raised regarding a lack of technology infrastructure in target countries, along with inadequate educational equipment, shortage of qualified instructors, lack of familiarity with distance learning for the general population, time commitments required of students who likely will have full time jobs, keeping students in the region after program completion in order to meet regional needs, and diffi- 
culties arising from limited finance options for students. Finally, language issues were also raised as a potential challenge, with some participants advocating for instruction in Russian while others preferred English or their main national language.

\section{Phase 2: Second Round Analysis}

Based on the identification of the actual learning needs in Phase 1, key tasks for Phase 2 included further data collection and analysis to support the generation of recommendations related to: curriculum topics; elearning capacity; curriculum format and delivery; content and pedagogical issues; and language of instruction. Given the constraints of reality such as a limited timeline and resources as well as access to a wider range of data, there were some limitations on the team's ability to collect and analyze data in an ideal fashion, particularly related to e-learning capacity. At the same time, these limitations provide a valuable opportunity to demonstrate how front-end analysis can still generate useful, evidence-driven recommendations when the realities of time and money are obstacles to a modelperfect process.

Curriculum topics. The team identified the following data as necessary to develop a deeper understanding of relevant course content needs:

- Additional private sector perspectives. Because only one private sector representative had been able to attend the in-person workshops, individual interviews were conducted with four private sector representatives following a semi-structured interview protocol that covered the major issues that were explored during the workshops. These areas included current job tasks, necessary skills, gaps or anticipated needs, and desired content. These interviews were analyzed and recorded using the framework that emerged from the workshops by synthesizing interview data into the broader workshop data themes.

- Benchmarking of existing educational programs in food security. A total of twenty existing educational programs in food security, ranging from self-paced online courses to $\mathrm{PhD}$ programs, were reviewed (note: 23 programs were identified, but three included insufficient information on curriculum to be included in the benchmarking data). Drawing on published descriptions of courses, curriculum topics were identified and incorporated into the master matrix developed during Phase 1. This benchmarking was intended both to identify current standards for curricula in food security as well as uncover potential gaps in existing programming that may have presented an opportunity for a competitive advantage.

- Individual course topic demand rankings. Once interview and benchmarking data had been added to the master course topics matrix, a survey was developed and sent electronically to all workshop participants. The survey included all potential course topics (for example, food security assessment; food security policy, human and rural development, monitoring and evaluation, etc.) identified in the workshops, interviews, and benchmarking survey. Respondents were asked to rank their personal demand for each topic on a scale from 1 (no interest) to 5 (strongly interested/I would register for this course). This step was similar to the foldback analysis described by Loos (1995), in which qualitative findings from initial data are used to build quantitative collection instruments in subsequent data collection rounds. Twelve subjects out of 29 completed the survey, representing a $41 \%$ response rate.

The private interviews supplemented the workshop data with additional perspectives, while the benchmarking process generated external data from established competitors as a gauge for existing performance standards. Finally, by surveying workshop participants on an individual basis several weeks after the workshop, it provided them with an opportunity to not only confirm the analysis team's interpretation of their expectations, but to also privately reassess the importance of topics raised in the workshop without any influences from the group. Taken together, these datasets offer a richer understanding of curriculum needs than any one might offer on its own. Once data collection was complete, it became necessary to integrate the three primary data pools regarding course topics in order to arrive at recommendations for the issues that would be most relevant to this food security learning program, given market needs and expectations.

This integration presented a challenge, as the data did not share the same scales; the workshop and benchmarking raw scores represented the number of times a topic was mentioned (in discussions or course descriptions), while the raw scores from the individual surveys represented the average value that respondents placed on a topic. Furthermore, the low response rate to the survey required a cautious approach to weighting its results in relation to other data. A ranking system was constructed as a way to compare the importance placed on curriculum topics across all dataset. In brief, each raw score was converted to an ordinal score and sorted from highest (most valued) to lowest (least valued) within each conceptual domain and each dataset. The top topics within each of the five conceptual domains (ranging from one quarter to one third of the identified topics, depending on the total number of topics) from all three datasets were added to a master matrix. Next, the mean of all three rankings for each topic was calculated and topics were sorted by mean ranking score to determine the most desired courses within each domain. The top half of topics in a given conceptual domain, as well as any topics ranked first within an individual dataset, were identified as being the most valued for a food security curriculum. For the socio-political and biophysical domains, which had the highest number of potential topics, a secondary analysis was performed, comparing the findings with curriculum topics included in comparable Master's programs in order to lend an additional layer of validity to the subsequent recommendations.

While this approach does have limitations (in particular, the ranking hierarchy did not reflect the magnitude of difference between two topics, only their position relative to each other), it does provide a basis of comparison when dealing with diverse datasets. The resulting findings were carefully considered within the con- 
text of all relevant data and analysis and the approach proved to be reasonable and useful for this situation. See Table 1 for an illustration of each of the ranking results for each data source, as well as the integrated average of the rankings for each topic, which allowed us to provide an overall ranking for each topic, and provide the basis for a potential order of priority.

E-learning capacity. Both the project team and the end-user workshop participants identified e-learning as an important consideration for the proposed project, with implications for curriculum format and pedagogy. A comprehensive assessment tool for existing elearning design and development capacity was developed in order to better understand these dimensions. The instrument assessed faculty availability and experience in designing and/or delivering e-learning content as well as resources available in reference to e-learning design, development, marketing, technical needs, and incentives for students and teachers. Due to resource limitations and limited access to key sources at the university (to which the institute was affiliated) that would be hosting the program, the instrument was not completed. As such, it was not possible to identify or validate, data-driven needs in this area.

In lieu of this, the needs analysis team developed a self-assessment tool that the institute could use at a later date to assess e-learning capacity in terms of e-learning design and development (EDD) experience and time commitment (TC); both individual and institutional capabilities could be assessed via this instrument. Users could rate themselves (or their institution) as either high or low on both dimensions, leading to four scenarios: high EDD, high TC; high EDD, low TC; low EDD, high TC; and low EDD, low TC. For each scenario, general recommendations and strategies based on best practices in the field were developed (3-5 per scenario), and a cost-consequence analysis (CCA) was conducted (Kaufman and Guerra-López, 2013). The CCA analyzed each recommendation in terms of its estimated time commitment, potential costs, potential risks associated with not implementing the recommendation, and its potential value or impact on performance. See Table 2 for a sample of the CCA. Which includes time estimates, cost considerations, risks, and potential value/ cost for each of the recommendations.

Course duration and delivery. As mentioned before, because a primary intention of the program was the establishment of a Master's degree program, the context analysis also led the team to identify any institutional requirements that might be relevant to the program. This involved research to uncover any national regulations governing the host university as well as regional guidelines outlined by the European Credit Transfer and Accumulation System (ECTS), as adherence to their requirements would lend further credibility to the program and facilitate attendance for students

Table 1

Topic Rankings in the Socio-Political Conceptual Domain*

\begin{tabular}{|c|c|c|c|c|c|}
\hline \multirow{2}{*}{\multicolumn{2}{|c|}{$\begin{array}{l}\text { Socio-political topics } \\
\text { (aggregated top ten topics } \\
\text { from each dataset; } 1-40 \text { scale) }\end{array}$}} & \multicolumn{4}{|c|}{ RANKING } \\
\hline & & $\begin{array}{l}\text { Workshop, } \\
\text { interviews, } \\
\text { internal review }\end{array}$ & $\begin{array}{c}\text { External } \\
\text { benchmarking } \\
\text { (all programs) }\end{array}$ & $\begin{array}{l}\text { Course } \\
\text { rankings }\end{array}$ & $\begin{array}{c}\text { Average } \\
\text { Rank }\end{array}$ \\
\hline 1 & Food security policies \& policy development & 3 & 2 & 1 & 2.00 \\
\hline 2 & Food security assessment & 14 & 3 & 1 & 6.00 \\
\hline 3 & Market analysis/forecasting & 1 & 8 & 10 & 6.33 \\
\hline 4 & Econ/geopolitical analysis & 2 & 5 & 19 & 8.67 \\
\hline 5 & Research/research methods & 5 & 8 & 14 & 9.00 \\
\hline 6 & Human \& rural development & 15 & 3 & 10 & 9.33 \\
\hline 7 & Policy analysis/forecasting & 5 & 21 & 6 & 10.67 \\
\hline 8 & Legislation (domestic \& international) & 5 & 13 & 19 & 12.33 \\
\hline 9 & Poverty \& inequality (factors/influences) & 15 & 13 & 10 & 12.67 \\
\hline 10 & International trade & 11 & 7 & 21 & 13.00 \\
\hline 11 & Global food/agriculture systems & 15 & 17 & 8 & 13.33 \\
\hline 12 & FS strategy \& strategy development & 3 & 40 & 1 & 14.67 \\
\hline 13 & Food security concepts/principles & 40 & 1 & 5 & 15.33 \\
\hline 14 & Simulation/forecasting methods/tools & 6 & 30 & 14 & 16.67 \\
\hline 15 & Statistics & 6 & 8 & 37 & 17.00 \\
\hline 16 & Econometrics & 5 & 30 & 17 & 17.33 \\
\hline 17 & Policy implementation & 12 & 30 & 10 & 17.33 \\
\hline 18 & Agriculture in economic development & 15 & 30 & 8 & 17.67 \\
\hline 19 & Regional issues in food security & 40 & 13 & 1 & 18.00 \\
\hline 20 & International development & 40 & 5 & 27 & 24.00 \\
\hline 21 & Resilience in food security & 40 & 30 & 7 & 25.67 \\
\hline
\end{tabular}


Table 2

Sample Cost-Consequence Analysis (CCA) for E-learning Capacity Recommendations for High Expertise, Low Time Commitment Scenario

\begin{tabular}{|c|c|c|c|c|}
\hline Recommendations & Time & Cost Considerations & Risk & Value/Impact \\
\hline $\begin{array}{l}\text { Prioritize e-learning offerings in } \\
\text { the forms of: } \\
\text { - Self-directed, self-paced, } \\
\text { individual, interactive e- } \\
\text { tutoring systems } \\
\text { Online or CD-based or Mo- } \\
\text { bile app-based tutorials, } \\
\text { quizzes/tests/exams } \\
\text { Web-supplemented e- } \\
\text { learning with the majority of } \\
\text { teaching and learning activi- } \\
\text { ties in face-to-face settings } \\
\text { Peer coaching or peer men- } \\
\text { toring }\end{array}$ & $\begin{array}{l}\text { This minimizes } \\
\text { the time com- } \\
\text { mitment re- } \\
\text { quired from } \\
\text { institute faculty }\end{array}$ & $\begin{array}{l}\text { Assumption is that there is } \\
\text { high internal expertise, } \\
\text { which means that there } \\
\text { would not be significant } \\
\text { cost investments other } \\
\text { than development of } \\
\text { course materials. If exper- } \\
\text { tise is low, significant up- } \\
\text { start costs for instructional } \\
\text { designers and developers, } \\
\text { as well as development of } \\
\text { materials (e.g. mobile app } \\
\text { based tutorials) }\end{array}$ & $\begin{array}{l}\text { It is not the most } \\
\text { conducive option } \\
\text { for developing } \\
\text { institute faculty } \\
\text { capacity, as it } \\
\text { rests on the as- } \\
\text { sumption that } \\
\text { there is high ca- } \\
\text { pacity already } \\
\text { within institute. }\end{array}$ & $\begin{array}{l}\text { Allows institute to } \\
\text { launch their e- } \\
\text { learning program } \\
\text { more quickly and } \\
\text { fully. }\end{array}$ \\
\hline $\begin{array}{l}\text { Prioritize e-learning on content } \\
\text { and subject areas which require } \\
\text { less frequent updates (e.g., fun- } \\
\text { damental sciences, theories) }\end{array}$ & $\begin{array}{l}\text { Some time } \\
\text { commitment } \\
\text { upfront to } \\
\text { design and } \\
\text { develop the } \\
\text { initial e- } \\
\text { learning ver- } \\
\text { sions. Little } \\
\text { maintenance } \\
\text { time required }\end{array}$ & $\begin{array}{l}\text { Cost are controlled be- } \\
\text { cause one version of the } \\
\text { course can last longer, } \\
\text { with minimal require- } \\
\text { ments of updates (costs } \\
\text { are incurred primarily } \\
\text { through "time/labor" and } \\
\text { to a lesser degree on tech- } \\
\text { nology infrastructure) }\end{array}$ & $\begin{array}{l}\text { Risk of not pro- } \\
\text { gressing to other } \\
\text { e-learning topics }\end{array}$ & $\begin{array}{l}\text { Opportunity to devel- } \\
\text { op full e-learning } \\
\text { courses from the very } \\
\text { beginning. These } \\
\text { could become the } \\
\text { core of the on-line } \\
\text { offerings }\end{array}$ \\
\hline $\begin{array}{l}\text { Additional teaching and sup- } \\
\text { porting staff }\end{array}$ & $\begin{array}{l}\text { Alleviates time } \\
\text { requirements } \\
\text { from full time } \\
\text { faculty }\end{array}$ & $\begin{array}{l}\text { Salaries plus benefits paid } \\
\text { out }\end{array}$ & $\begin{array}{l}\text { Additional teach- } \\
\text { ing and sup- } \\
\text { porting staff } \\
\text { might end up } \\
\text { with all (or prima- } \\
\text { ry) online respon- } \\
\text { sibilities, and } \\
\text { deter the online } \\
\text { capacity building } \\
\text { of current teach- } \\
\text { ing and support } \\
\text { staff }\end{array}$ & $\begin{array}{l}\text { From an implementa- } \\
\text { tion perspective, this } \\
\text { might be a feasible } \\
\text { approach to rolling } \\
\text { out the e-learning } \\
\text { curriculum, and pro- } \\
\text { vided there is a ca- } \\
\text { pacity development } \\
\text { plan for current } \\
\text { teaching and support } \\
\text { staff that is well exe- } \\
\text { cuted }\end{array}$ \\
\hline $\begin{array}{l}\text { Outsourcing e-learning technical } \\
\text { support for instructors and stu- } \\
\text { dents }\end{array}$ & $\begin{array}{l}\text { Minimal time } \\
\text { commitment } \\
\text { for tech sup- } \\
\text { port. Time can } \\
\text { be reallocated } \\
\text { for instruction- } \\
\text { al/ pedagogical } \\
\text { support }\end{array}$ & Vendor fees & $\begin{array}{l}\text { Outsourcing pro- } \\
\text { vides instant sup- } \\
\text { port, but does } \\
\text { little to build } \\
\text { internal capacity. }\end{array}$ & $\begin{array}{l}\text { From an implementa- } \\
\text { tion perspective, this } \\
\text { might be a feasible } \\
\text { approach to rolling } \\
\text { out the e-learning } \\
\text { curriculum, and pro- } \\
\text { vided there is a ca- } \\
\text { pacity development } \\
\text { plan for current } \\
\text { teaching and support } \\
\text { staff that is well exe- } \\
\text { cuted }\end{array}$ \\
\hline
\end{tabular}


from the five end-user nations. ETCS regulations primarily address the number of course hours (spent in instruction and self-study) required per credit as well as the number of credit hours needed for full-time study per academic year. The host country's regulations also addressed the number of credits required for a Master's degree, outlined requirements for the ratio of time that courses could spend in lectures vs. other types of instruction or self-study, and set a minimum number of in -residency credit hours. Furthermore, both the client and the end-user stakeholders had expressed a desire for shorter, more time-intensive courses as it was anticipated this format would be more viable for potential students. In order to make this information useful within the context of this project and generate recommendations for the client, the team developed a matrix that compared credit hours, course hours, course duration (in weeks), along with best practices for e-learning, to make recommendations regarding the best use of online, in-person, and hybrid courses given specific course duration scenarios.

Content and pedagogical issues. In light of stakeholder interest in developing e-learning components, it was important to provide recommendations that addressed what types of content are best suited to online vs. face-to-face learning. Likewise, given end-user and client interest in constructivist instructional practices with an emphasis on hands-on learning, guidelines were needed to help the client identify opportunities to integrate these experiences in online and face-to-face contexts. For this portion of the analysis phase, best practic-

Table 3

Final Curriculum Topic Recommendations

\begin{tabular}{|c|c|}
\hline Conceptual Domain & Topics \\
\hline \multirow[t]{11}{*}{ Socio-political } & Food security policies \& policy development \\
\hline & Food security assessment \\
\hline & Market analysis/forecasting \\
\hline & Econ/geopolitical analysis \\
\hline & Research/research methods \\
\hline & Human \& rural development \\
\hline & Policy analysis/forecasting \\
\hline & Legislation (domestic \& international) \\
\hline & Poverty \& inequality (factors/influences) \\
\hline & International trade \\
\hline & Food security concepts/principles \\
\hline \multirow[t]{6}{*}{ Management \& Leadership } & Project planning \& management \\
\hline & Internal coordination \\
\hline & Finance/budgeting \\
\hline & Communication/marketing/PR \\
\hline & External coordination \\
\hline & Food security educational program management \\
\hline \multirow[t]{2}{*}{ Monitoring \& Evaluation } & Monitoring projects/programs/policies \\
\hline & Policy impact evaluation \\
\hline \multirow[t]{10}{*}{ Biophysical } & Sustainable development/production \\
\hline & Food safety/quality \\
\hline & Agricultural production/agronomy \\
\hline & Technology \\
\hline & Nutrition \\
\hline & Hydrology/water systems \\
\hline & Food standards/regulations \\
\hline & Agricultural R\&D \\
\hline & Food supply chain \\
\hline & GIS \\
\hline Outreach & Farmer training \\
\hline
\end{tabular}


es for adapting content and pedagogy to specific learning environments were identified and synthesized in order to provide the client with guidelines for future decision-making. As further support for sound instructional decisions, a method-means analysis (Kaufman and Guerra-López, 2013) was conducted; this process involved recommending course duration options and outlining advantages and disadvantage for each option, with the goal of helping the client contextualize the opportunities and limitations of their solution choices in relation to its own goals and resources.

Language of instruction. Finally, an important area of concern for all stakeholders was the language of instruction to be used in the programming. The target audience spanned five countries with different primary languages, with varied capabilities in common languages such as Russian and English. To augment language preference data gathered during the end-user workshops (which showed a near-even split between the two common languages), benchmarking data were col- lected on existing food security education programs (described earlier). These data showed that all but two of the 23 programs were conducted solely in English, with all eight Master's programs conducted in English only. Furthermore, concerns had been raised by a few end-users that the target student population (under age 30 ) in some of the included countries had very low levels of fluency in Russian, and the international development agency (the funder) had an established mandate to build capacity and sustainability within the institute. This information was integrated and used to drive the final language of instruction recommendation, which was primarily Russian.

\section{Phase 3: Recommendations}

Drawing on the data collection and analyses conducted during Phase 2, evidence-driven recommendations were developed during Phase 3. As noted earlier, it was not possible to document specific needs in all areas (such as e-learning capacity), so the team used

\section{EDDD (Expertise in e-learning design \& development) Choose which description most closely matches your institution (or self)}

Well-staffed with experienced experts (or equipped with personal expertise) in all of the following areas: instructional design, emerging learning technology, Course Management System (e.g., MOODLE), educational multimedia design and development
Staffed with experts (or equipped with personal expertise) in two (or less) of the following areas: instructional design, emerging learning technology, Course Management System (e.g., MOODLE), educational multimedia design and development

\section{TC (Time commitment)}

Choose which description most closely matches your institution (or self)

With ALL of the following:

- Institutional policies and incentive systems recognize the additional time and efforts it requires to deliver and update e-learning courses and programs, compared to face-to-face offerings;

- Awareness of the additional time commitment required for e-learning delivery, site maintenance and content updates on the individual, departmental and institutional levels;

- Readiness to devote the additional time for elearning delivery, site maintenance and content updates on the individual, departmental and institutional levels
With ANY of the following:

- No clearly stated institutional policies or incentive systems to recognize the additional time and efforts it requires to deliver, maintain and update e-learning courses and programs, compared to face-to-face offerings;

- Lack of knowledge or understanding of the additional time it requires for e-learning delivery and update, compared to face-to-face offerings;

- Faculty are not granted with additional time for elearning delivery, site maintenance or content updates

- Departments and institutions do not support regularly scheduled e-learning content updates or site/system maintenance 
available data to provide self-assessment tools based on likely scenarios for the client to use in the future. Recommendations for curriculum topics, e-learning design and development, course duration and credit hours, content and pedagogical approaches, and language of instruction are summarized below.

Curriculum topics. Out of a pool of 90 potential topics, 30 were identified as being highly rated by workshop groups, benchmarking data, and individual end-users. Table 3 illustrates the main conceptual domains, along with the specific potential course topics. For example, under the socio-political domain, topics like food security policies and policy development, food security assessment, market analysis/forecasting, Econ/ geopolitical analysis were some of the top topics that emerged.

E-learning design and development capacity. As mentioned, a self-assessment tool was developed for the client. Figure 1illustrates the e-learning self-capacity assessment that was developed to determine the level of expertise in e-learning design and development (high vs. low), as well as the level of time commitment available to support e-learning (high vs. low). Figure 2 then provides recommendations given each of the four scenarios (1) high e-learning design \& development expertise-low time commitment; (2) high e-learning design \& development expertise-high commitment; (3) low elearning design \& development expertise-low time commitment; (4) low e-learning design \& development expertise-high commitment.

In addition to general best practices for e-learning that were included in the report, client-specific recommendations were included for developing e-learning capacity within the target institute, both leadership and faculty. Table 4 presents examples of the recommendations that were made specifically for the institute leadership and faculty. For example, a key recommendation

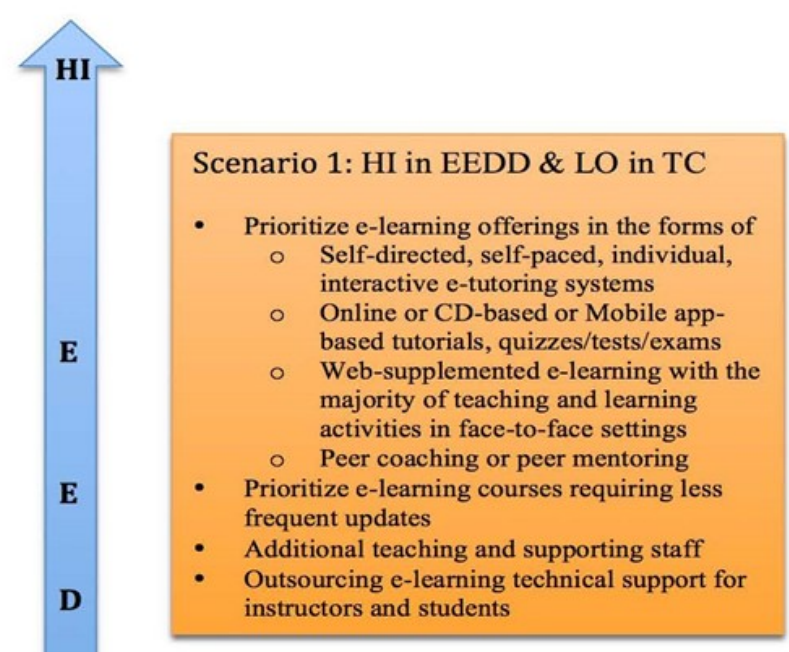

Scenario 3: LO in EEDD \& LO in TC

- Short term courses

- Face-to-face offerings

- Translate successful face-to-face courses to "shovel ware" e-learning materials

- Using MOODLE for simple tasks (e.g., sharing learning materials, testing, submitting homework, etc.) as a start

\section{Scenario 2: $\mathrm{HI}$ in EEDD \& $\mathrm{HI}$ in $\mathrm{TC}$}

Start with exemplary e-learning courses as part of a degree programs

Promote quality e-learning in a variety of forms

Collaborate for interdisciplinary offerings

Sharing e-learning offerings and resources

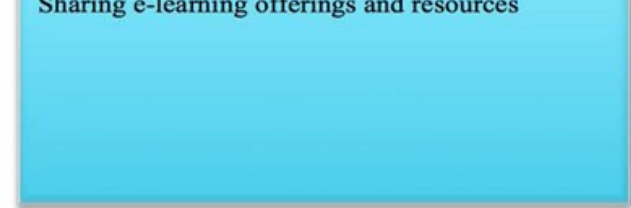

LO in EEDD \& HI in TC

- Adapt existing e-learning courses, resources and programs

- Adapt selected MOOC as part of the curriculum

- Prioritize offerings in the forms of: $\circ$ face-to-face

- Short term course

field schools

- lab learning sessions

practicums

$\circ$ blended

- Build supportive learning communities \& communities of practice

- Support faculty development for EEDD growth

LO

HI

Figure 2. E-learning Capacity Scenarios and Recommendations 
for leadership was that expectations for e-learning design, development, and facilitation be explicitly clarified (who, when, how, etc.). One of the recommendations made to faculty was that they proactively seek to observe other faculty who are more experienced with successfully teaching online.
Course duration and format. Data on end-user preferences and relevant academic regulations were integrated with best practices for instructional design to develop a matrix illustrating the relationship between these variables (see Figure 3) and arrive at recommendations for course duration and format, outlined below.

Table 4

E-learning Capacity Development Recommendations for the Institute

Recommendations for Institute Leadership

- Ensure the expectation for e-learning design, development and delivery is shared by all institute leadership and faculty, including specific milestones (e.g. which faculty will teach online, which courses, which semesters, with what support, etc.)

- Improve EFCS faculty skills and knowledge in e-learning design, development, and delivery through professional development activities (for example, e-learning design instructional guide and upcoming March 2014 workshop)

- Provide sufficient time and incentives (e.g. release from teaching other courses during the first year teaching online) for institute faculty to devote to the adaptation of their traditional face-to-face courses to e-learning courses, which will take significant more effort.

- Provide technical staff that can offer technical support for faculty and students

- Provide instructional design staff that can support the design and development of courses, with the involvement of faculty (in order to support faculty capacity to be enhanced). For example, the instructional design staff can support with basic online course structure elements (e.g. general online course information to students, netiquette, discussion, course guide templates, unit content folders, unit agenda templates, etc.)

- Provide student assistant support to assist with course management (taking care that faculty are still leading course facilitation in order to support faculty capacity development, rather than transferring online facilitation to student assistants, which does little to develop faculty capacity)

\section{Recommendations for Institute Faculty}

- Observe or ask for "guest" privileges in online courses taught by faculty with demonstrated expertise and success with applying online best practices (in design and facilitation)

- If full instructional design support is not yet available, start with using MOODLE for one or more simple tasks: sharing learning materials and readings, testing, submitting homework, etc.

- As an initial step, translate successful face-to-face courses to "shovel ware" e-learning materials: simply digitizing learning materials and making them available for supplemental e-learning. This can be done as faculty work on developing their e-learning capacity, not as a substitute.

- Build supportive learning communities \& communities of practice (COP) by using MOODLE to set up student discussion forums and blogs that you can moderate

- As a transition to improved capacity, focus on the development of relatively short- to mid-term courses (6-8 weeks) that can better allow you to integrate e-learning best practices in a smaller scale (relative to a full 20 semester course) 


\begin{tabular}{|l|r|r|r|r|r|r|r|r|}
\hline & $\mathbf{1}$ & $\mathbf{2}$ & $\mathbf{4}$ & $\mathbf{6}$ & $\mathbf{8}$ & $\mathbf{1 2}$ & $\mathbf{1 6}$ & $\mathbf{2 0}$ \\
\hline ECTS Credits $^{2}$ & 1.5 & 3 & 6 & 9 & 12 & 18 & 24 & 30 \\
\hline Course Hours $^{3}$ & 45 & 90 & 180 & 270 & 360 & 540 & 720 & 900 \\
\hline
\end{tabular}

Face-to-Face $\quad \rightarrow \rightarrow \rightarrow \rightarrow \rightarrow \rightarrow \rightarrow \rightarrow$ Blended/Hybrid $\rightarrow \rightarrow \rightarrow \rightarrow \rightarrow \rightarrow \rightarrow \rightarrow$ Fully Online

\footnotetext{
This chart assumes that 45 hours a week are available for course hours ( 9 hours a day, Monday-Friday).

${ }^{2}$ Each ECTS credit is equivalent to 25-30 course hours. To err on the side of caution, we have used the higher figure to plot the number of course hours for the duration scenarios.

${ }^{3}$ This chart assumes that the course hours estimation includes homework time (at least $50 \%$ ) with the remaining time allotted to instruction (not more than $20 \%$ lecture hours).
}

Figure 3. Course Duration and Format Matrix

\section{Recommendations for short-term courses}

- For the shorter professional development (nondegree) courses (from one week to a few weeks in duration), a face-to-face delivery approach would be a better fit.

- Courses ranging from four to eight weeks (and beyond) are good candidates for a hybrid approach that blends face-to-face and e-learning (taking under consideration topics that are appropriate for this duration as discussed below).

\section{Recommendations for Master's courses}

- Courses that are longer in duration, from 12 weeks up to 20 (the latter being the equivalent of a Russian semester), are generally appropriate candidates for full online delivery as they can more feasibly incorporate a full range e-learning best practices.

Course content and pedagogy. Recommendations for course content and pedagogy relative to course duration and delivery format were developed to address end-user preferences for active, hands-on instructional strategies while also accounting for how the nature of the content might be best matched to the duration and delivery.

Recommendations for short-term courses (face-toface delivery):

- Content is subject to frequent changes or requires updating on a regular basis in order to stay meaningful and relevant.

- Content can be covered in the given short-term duration (ranging from 4 days to 4 weeks) OR content can be divided into smaller topics that can be delivered in individual modules; depending on the nature of the content, the modules may be offered independently or as part of a linked series with all required to meet a competency.

- Content delivery will benefit from hands-on or practical pedagogical strategies.
Recommendations for Master's length courses (online or hybrid delivery):

- Content is fundamentally static and does not change substantially from year-to-year.

- Content is lengthy, complex, and/or difficult to subdivide in a meaningful way.

- Content requires a minimum of six weeks (and beyond) to be effectively delivered using best instructional practices.

- Content can be effectively taught without hands-on or applied teaching approaches OR with applied learning activities that students can complete on their own (such as case studies) OR in a blended delivery format, with the face-to-face components focused on hands-on pedagogical strategies.

\section{Conclusion}

This case study illustrates one approach to conducting stakeholder-driven learning analysis while working within data collection and timeline constraints. This case study begins with the selected solution (i.e. a learning program), and delves more deeply into the specific learning needs and expectations held by stakeholders in the transfer context in order to articulate specific solution requirements that will be a critical input for design and development ((Tessmer \& Richey, 1997).

As higher education institutions face mounting pressures to meet market needs by developing relevant degree programs that will position graduates for meaningful employment (Guerra \& Rodriguez, 2005; Kaufman, Watkins, \& Guerra, 2002), it will be critical for institutional leaders and instructional designers to consider using an outside-in approach as demonstrated in this case study. Instead of relying on assumptions or perceptions that may be inadvertently biased with an excessive "supply" lens (what the faculty can and want to offer), design teams would contribute greater value by involving external stakeholders (including those in the 
position to hire future graduates) in the definition of needs and requirements. This would become a key input to drive the design and development process. The resulting offering, will only be as good as the decisions that are made throughout the process, and those decisions will only be as good as the evidence that informs them (Guerra-López \& Norris-Thomas, 2011).

\section{Author Note}

Corresponding Author: Ingrid Guerra-López, Ph.D.; Learning Design \& Technology Program and Institute for Learning and Performance Improvement, Wayne State University, 399 Education Building, Detroit, MI 48202, ingrid.guerra-lopez@wayne.edu, 1-313-5771675.

\section{References}

Autry, A. M., Meurer, L. N., Barnabei, V. M., Green, S. S., Johnson-Masotti, A. P., Otto-Salaj, L. L., ... \& Simpson, D. E. (2002). A longitudinal women's health curriculum: A multi-method, multiperspective needs assessment. A merican Journal of Obstetrics and Gynecology, 187(3), S12-S14. doi:10.1067/mob.2002.127369

Dick, W., \& Carey, L. (1990). The systematic design of instruction. New York: HarperCollins.

Guerra, I. \& Rodriguez, G. (2005). Social responsibility and educational planning. Performance Improvement Quarterly, 18(3), 56-64.

Guerra-López, I. \& Norris-Thomas, M. (2011). Making sound decisions: A framework for judging the worth of your data. Performance Improvement Journal, 50(5), 37-44

Guerra-López, I. (2012). Needs assessment: A definition. In R. Richey (Ed.). Encyclopedia of Definitions in Instructional Technology. New York: Springer-AECT.

Jeffrey, L., \& Brunton, M. (2010). Identifying competencies for communication practice: A needs assessment for curriculum development and selection in New Zealand. Public Relations Review, 36(2), 202-205. doi:10.1016/j.pubrev.2010.02.003

Kaufman, R. \& Guerra-López, I. (2013). Needs Assessment for Organizational Success. Virginia: American Society for Training \& Development.

Kaufman, R., Watkins, R., \& Guerra, I. (2002). Getting valid and useful educational results and payoffs: We are what we do, say, and deliver. International Journal of Educational Reform, 11(1), 77-92.

Loos, G. P. (1995). A blended qualitative-quantitative assessment model for identifying and rank-ordering service needs of indigenous peoples. Evaluation and Program Planning, 18(3), 237-244.
Meyer, M. H., \& Bushney, M. J. (2008). Towards a multi-stakeholder-driven model for excellence in higher education curriculum development. South African Journal of Higher Education, 22(6), 12291240.

Molenda, M., \& Boling, E. (2008). Creating. In Januszewski, A. and Molenda, M. (Eds), Educational Technology: A Definition with Commentary, pp 81139. Routledge.

Smith, P. L., \& Ragan, T. J. (1999). Instructional design, $2^{\text {nd }}$ Edition. New York: Wiley.

Sutcliffe, N., Chan, S. S., \& Nakayama, M. (2005). A competency based MSIS curriculum. Journal of Information Systems Education, 16(3).

Tessmer, M., \& Richey, R. C. (1997). The role of context in learning and instructional design. Educational Technology Research and Development, 45(2), 85-115. 
